\title{
Desenvolvendo capacidades da inteligência emocional através do coaching
}

\author{
Jenifer Rosa Arruda ${ }^{1}$ \\ Jhony Pereira Moraes ${ }^{2}$ \\ Taís Colling ${ }^{3}$
}

\begin{abstract}
Resumo: O presente trabalho tem como objetivo compreender como o processo de coaching pode auxiliar no desenvolvimento dos componentes da inteligência emocional. $\mathrm{O}$ estudo acontece, especificamente, em torno de dois componentes: a autoconsciência e a autogestão. Para compreender o desenvolvimento desses componentes da inteligência emocional através do coaching são analisadas duas ferramentas: perguntas e crenças. $\mathrm{O}$ trabalho utiliza análise teórica, por meio de pesquisa bibliográfica, para obtenção de informações que sustentem a questão de estudo proposta. Os resultados alcançados com o estudo mostram que as ferramentas do coaching - perguntas e crenças - são capazes de auxiliar no desenvolvimento dos componentes da inteligência emocional - autoconsciência e autogestão, pois elas contribuem para a expansão da consciência da pessoa sobre ela mesma, ou seja, ampliando a autoconsciência. Essas ferramentas ajudam para que experiências sejam ressignificadas alterando a forma de resposta dos indivíduos e aprimorando sua autogestão.
\end{abstract}

Palavras Chave: Inteligência Emocional. Desenvolvimento. Autoconsciência. Autogestão. Coaching.

\section{Developing Emotional Intelligence capacities through the coaching}

Abstract: This study aims to understand how the coaching process can assist in the development of the components of emotional intelligence. The study take place specifically around two components: self-awareness and self-management. To understand the development of these components of emotional intelligence through coaching is analyzed two tools: questions and beliefs. This study uses theoretical analysis, through a bibliographic research, to obtain informations that sustain the issue of study proposal. The results achieved with the study shows that coaching tools - questions and beliefs - are able to assist in the development of the components of emotional intelligence - self-awareness and self-management - as they contribute to the expansion of consciousness of the person about herself expanding self-awareness . These tools help to experiences are re-signified by changing the form of response of individuals and enhancing their self-management.

Key Words: Emotional intelligence. Development. Self-awareness. Self-management. Coaching.

\section{Desarrollando capacidades de la inteligencia emocional a traves del coaching}

Resumen: El presente trabajo tiene como objetivo comprender cómo el proceso de coaching puede auxiliar en el desarrollo de los componentes de la inteligencia emocional. El estudio ocurre, específicamente, en torno a dos componentes: la autoconciencia y la autogestión. Para comprender el desarrollo de estos componentes de la inteligencia

\footnotetext{
${ }^{1}$ Mestranda em Gestão de Pessoas do Programa de Pós-graduação em Administração da Universidade Federal do Rio Grande do Sul (UFRGS).

${ }^{2}$ Mestrando em Administração (área de Gestão de Pessoas e Relações de Trabalho) pelo Programa de PósGraduação em Administração da UFRGS (PPGA/UFRGS)
}

${ }^{3}$ Possui graduação em Administração pela Universidade de Passo Fundo (UPF - 2013). Pós Graduada em Economia e Gestão Empresarial pela Universidade de Passo Fundo (UPF - 2016). Cursa Ciências Contábeis na Universidade de Passo Fundo (UPF). 
emocional a través del coaching, se analizan dos herramientas: preguntas y creencias. El trabajo utiliza análisis teórico, por medio de investigación bibliográfica, para obtener informaciones que sustenten la cuestión de estudio propuesta. Los resultados obtenidos con el estudio muestran que las herramientas del coaching - preguntas y creencias - son capaces de auxiliar en el desarrollo de los componentes de la inteligencia emocional autoconciencia y autogestión, pues ellas contribuyen a la expansión de la conciencia de la persona sobre ella misma, o sea, ampliando la autoconciencia. Estas herramientas ayudan a que las experiencias sean significadas nuevamente cambiando la forma de respuesta de los individuos y mejorando su autogestión.

Palabras clave: Inteligencia Emocional. Desarrollo. Conciencia de sí mismo. La autogestión. Coaching.

\section{Introdução}

O tema inteligência emocional está em evidência atualmente, pois passou-se a entender como é importante o ser humano, que é a base da força de trabalho e quem efetivamente move as organizações para o alcance de seus objetivos.

O proposto para este estudo vem ao encontro com a realidade atual de muitas empresas que compreendem, assim como Goleman, Boyatzis e McKee (2002), que identificar certos hábitos particulares enraizados em algumas equipes ou organizações e que acabam por afetar seus comportamentos são parte da compreensão da realidade emocional. Líderes que se utilizam da inteligência emocional a seu favor buscam enxergar tais hábitos e tudo aquilo que lhes dá sustentação e dessa forma conseguem trabalhar com as emoções das pessoas e também com a realidade emocional dos grupos (GOLEMAN; BAYATZIS; MCKEE, 2002).

De acordo com França (2010), fatos como incertezas oriundas de fusões, incorporações, novos conhecimentos, diminuição ou eliminação de postos de trabalho, fatos que marcam o cenário atual das empresas, as perspectivas entre trabalho, família, o consumo e possíveis sintomas de estresse influenciaram novas atitudes das organizações e também evidenciaram a necessidade de mudança no modo de vida das pessoas, propiciando a busca de fatores para a construção de uma nova realidade empresarial e pessoal. Sendo assim, diante de um contexto mundial de mudanças organizacionais constantes, é indispensável que as lideranças guiem de forma eficaz seus liderados, nesse sentido, Goleman (2015) afirma que esses líderes considerados eficazes possuem como característica crucial incomum o alto grau de inteligência emocional, que segundo o autor é a condição indispensável para a liderança.

Neste sentido, o presente estudo tem como objetivo compreender a evolução das capacidades da Inteligência Emocional por meio do processo de coaching. As capacidades da Inteligência emocional destacadas para o estudo foram Autoconsciência e Autogestão. A 
seguir serão apresentados conceitos, origem e definições de Inteligência Emocional e das capacidades citadas. Também serão expostos conceitos e definições sobre coaching e algumas de suas ferramentas que possam contribuir para o desenvolvimento de capacidades da inteligência emocional em relação aos componentes autoconsciência e autogestão

\section{Metodologia}

Este estudo está configurado como uma pesquisa de cunho bibliográfico, exploratória e explicativa, e com abordagem qualitativa. Primeiramente, Lakatos e Marconi (2010) afirmam que a pesquisa é um procedimento reflexivo, de tratamento científico, que visa conhecer realidades. Para Gil (2008), a pesquisa objetiva o descobrimento de respostas a problemas através de técnicas/procedimentos científicos.

Nesse sentido e explicando a metodologia empregada neste trabalho, Thums (2000) diz que a pesquisa bibliográfica estrutura-se em obras literárias, extraindo suas teorias, autores, quadros de referência e revisões de literatura. Assim, buscou-se na literatura existente livros e artigos com o objetivo de levantar dados que fomentem a questão de estudo proposta. Quanto ao caráter exploratório do estudo, o autor sustenta que os estudos exploratórios oferecem maior familiaridade com o problema pesquisado ou com as hipóteses construídas. Compõem-se, geralmente, por levantamentos bibliográficos, entrevistas, e análise de situações; além de adotarem - principalmente - os estudos de casos.

Em relação à pesquisa explicativa empregada aqui, Thums (2000) salienta que os estudos explicativos almejam determinar quais os fatores que influenciam na ocorrência de um fenômeno. Em muitos casos são combinados com pesquisas experimentais, ex-post-facto (a serem vistas adiante) e descritivas.

Por fim, a abordagem qualitativa do estudo é vista por Creswell (2010) como um tipo de pesquisa que busca compreender os significados dados por um grupo de indivíduos a um problema, explorando-o. Os dados são coletados no ambiente do participante, são analisados e possuem compreensão e interpretação individualizadas do problema.

\section{Fundamentação Teórica}

\subsection{Inteligência emocional - Origem e conceito}

Segundo Moscovici (1997), a aptidão geral intelectual foi a primeira concepção de inteligência. Nesse sentido, era considerada como a competência geral de resolver os 
problemas, por exemplo, a pessoa considerada mais inteligente era aquela que resolvesse melhor os problemas; a menos inteligente não obtinha êxito ao resolver os problemas, sobretudo, quando a situação a qual era exposta fosse nova, não possuindo recursos adquiridos anteriormente.

Ainda de acordo com o autor, a partir desse primeiro entendimento, originaram-se os testes de inteligência. Já o estudo de análise fatorial da inteligência teve início na década de 30, utilizando-se a metodologia estatística, com o intuito de distinguir os fatores que estivessem inseridos em um conjunto - chamado cluster. A partir desses estudos, já se tinha o conhecimento em relação a subdivisão da inteligência geral em vários tipos de inteligência. Mais adiante, nas décadas de 40 e 50, nascem os trabalhos pioneiros de Thurstone e Guilford. Thurstone foi o precursor da análise fatorial dos testes de inteligência. Howard Gardner retomou o desenvolvimento e a evolução do conceito fatorial de inteligência e em 1983 publicou seu livro, ele abriu o leque de inteligências múltiplas que permitiu um enfoque especial sobre inteligência emocional. (Moscovici,1997)

De acordo com a teoria das inteligências múltiplas, as pessoas podem apresentar deficiências em alguns aspectos da inteligência e serem notáveis em outros. Por exemplo, uma pessoa pode possuir escores muito baixos em medidas de capacidades verbais e matemáticas, e em contrapartida, apresentar um elevado grau de habilidades sociais e musicais e demonstrar competência para desempenhar atividades profissionais que tenham como foco essas capacidades (GAZZANIGA; HEATHERTON, 2005).

Para Gazzaniga e Heatherton (2005), a inteligência é um atributo empregado para descrever uma pessoa, com base nas suposições. Primeiro, que todo indivíduo tem uma gama de distintas capacidades. E segundo, a inteligência pode ser igualada a como um individuo é avaliado em uma escala de capacidades específica, de acordo com a cultura que o valoriza.

Com os trabalhos publicados por Daniel Goleman, em 1995, a teoria da Inteligência Emocional começou a ganhar popularidade. Porém, antes das publicações do referido autor, o estudo das emoções já havia se iniciado. A inteligência Emocional vem sendo pesquisada há, no mínimo, cinquenta anos. Assim, pode-se entender como um tema de estudo novo, porém largamente debatido por meio de outras nomenclaturas. A Inteligência Emocional tornou-se mais popular na metade da década de noventa, e o debate a seu respeito perdura até os dias de hoje. (SHAPIRO apud KERKOSKI, 2008). 
Para Moscovici (1997), a Inteligência Emocional é apenas um rótulo de contexto mercadológico. Algo que atrai a atenção, sendo um nome de impacto para vender. Uma denominação nova, que torna o assunto interessante para o leitor. No entanto, também acredita que a inteligência emocional teria vindo para atender a necessidade de se deixar de negligenciar a esfera emocional, o que tem ocorrido ao longo dos tempos e se tornado uma das carências da sociedade tecnológica. Para ilustrar, o autor apresenta o exemplo das famílias, que em sua maioria, não oferecem uma educação emocional às crianças. Segundo ele, os pais tendem a preocupar-se em demasia com a educação social, que tem como base as regras comportamentais e de conduta, sendo elas oriundas do que é aceito ou não pela sociedade em que vivemos. Os pais preocupam-se pouco em relação a parte emocional de seus filhos, em desenvolver a forma de como irão demonstrar e lidar com as suas emoções.

Ryback (1998), define inteligência emocional como sendo a habilidade das pessoas em utilizar a percepção no reconhecimento dos sentimentos que estão por trás da comunicação interpessoal, agindo com receptividade, de forma sincera e autêntica e suportando ao impulso de ter uma reação impensada. Também segundo Ryback (1998, p. 64), “a inteligência emocional integra a percepção das nossas emoções com o conhecimento intelectual do mundo a nossa volta".

A inteligência emocional, segundo Weisinger (2001), nada mais é do que a utilização inteligente das emoções, ou seja, utilizá-las de forma intencional para que trabalhem a seu favor. Usar as emoções como auxílio para escrever o comportamento e raciocínio com objetivo de aprimorar resultados. $\mathrm{O}$ autor também observa que a inteligência emocional pode ser usada tanto para ajudar a si mesmo (intrapessoalmente), quanto para ajudar outras pessoas (interpessoalmente).

Goleman (2011) relata que temos ações imediatas que acabam sendo predispostas por todos os tipos de emoções que vivenciamos. Cada emoção vivenciada aponta para uma certa direção que comprovou ser a mais apropriada, nos habituais desafios enfrentados pelo ser humano, ao longo da vida. O Autor caracteriza a inteligência emocional como:

[...] capacidade de criar motivações para si próprio e de persistir num objetivo apesar dos percalços; de controlar impulsos e saber aguardar pela satisfação de seus desejos; de se manter em bom estado de espírito e de impedir que a ansiedade interfira na capacidade de raciocinar; de ser empático e autoconfiante (GOLEMAN, 2011, p. 63). 
Weisinger (2001) entende que a inteligência emocional origina-se de quatro componentes, que funcionam como os componentes do DNA, porém, diferentemente do DNA biológico, os componentes da inteligência emocional conseguem ser desenvolvidos e com isso aumentar expressivamente a nossa inteligência emocional. Esses componentes, quando nutridos por experiências, possibilitam o desenvolvimento de habilidades e capacidades específicas, que irão compor o alicerce da inteligência emocional nos indivíduos. Estes quatro componentes são:

- A habilidade de perceber, expressar e avaliar de forma correta uma emoção;

- A habilidade de promover ou acessar sentimentos quando eles puderem facilitar o seu entendimento de si mesmo ou de outra pessoa;

- A habilidade de entender as emoções e o conhecimento proveniente delas;

- A habilidade de dominar as próprias emoções para fomentar o crescimento emocional e intelectual.

Goleman (2015), por meio de seus estudos, definiu quatro como sendo o número de componentes que caracterizam a inteligência emocional: autoconsciência, autogestão, empatia e habilidade social. Dois deles serão estudados em profundidade e apresentados a seguir.

\subsection{Componentes da inteligência emocional}

A inteligência emocional, segundo Goleman (2014), possui quatro componentes fundamentais, a autoconsciência, autogestão, empatia e a habilidade social. A seguir, para fins desse estudo, serão apresentados os componentes chamados autoconsciência e autogestão.

\subsubsection{Autoconsciência}

Compreender intimamente as próprias emoções, forças, fraquezas, necessidades e impulsos é o que significa a autoconsciência, e entendida como o primeiro componente da inteligência emocional. Ela se manifesta como franqueza e uma habilidade de se autoavaliar de maneira realista. Aqueles que são capazes de expor com clareza e abertamente o impacto que suas emoções exercem em seu trabalho são exemplos de pessoas com alto nível de autoconsciência (GOLEMAN, 2015). 
De acordo com Gordon (2003, p. 11), “a capacidade de acompanhar o próprio modo de pensar, detendo-nos para questionar os pensamentos e sentimentos como se nos observássemos de fora, é o que se chama de autoconsciência". Nesse mesmo sentido, Weisinger (2001) afirma que pessoas com a autoconsciência em grau elevado são capazes de atuar para que seus atos funcionem em seu benefício, pois conseguem monitorar e observar a si próprios em ação. Gordon (2003) ainda ressalta que para trocar os sentimentos por outros melhores, depois de ter consciência deles, além de recursos pessoais, pode ser necessário força de vontade.

Goleman (2015) afirma que as pessoas autoconscientes entendem as suas limitações e suas forças e ficam à vontade para dialogar a respeito delas. Além disso, costumam manifestar desejo por críticas construtivas. No entanto, aquelas consideradas com autoconsciência baixa entendem como uma ameaça ou sinal de insucesso a mensagem de que é necessário melhorar. Para Gordon (2003, p 11), “A autoconsciência deveria ser um processo construtivo, mas geralmente somos nossos críticos severos ou nos julgamos com excessivo rigor. Permitir que os fatos sejam reenquadrados de maneira positiva requer tempo e cabeça fria".

Indivíduos que possuem autoconsciência elevada não são nem críticos em excesso, nem possuem esperanças fora da realidade. São, na verdade, honestos consigo mesmo e com os outros. Eles percebem como seus sentimentos influenciam a eles, aos outros e ao seu desempenho profissional. Sendo assim, uma pessoa autoconsciente entende que se não consegue bons resultados sob prazos muito pequenos, tende a planejar seu tempo e antecipar o término do trabalho. Outro exemplo de alguém muito autoconsciente, é quando uma pessoa é capaz de recusar uma oferta de emprego por não se adequar aos seus princípios ou objetivos de longo prazo, mesmo sendo sedutora financeiramente. Vale destacar que a autoconsciência também está relacionada ao entendimento de cada um sobre seus próprios valores e propósitos (GOLEMAN, 2015).

\footnotetext{
Pessoas autoconscientes também podem ser reconhecidas por sua autoconfiança. Elas têm uma compreensão firme de suas capacidades e são menos passiveis de fracassarem, por exemplo, por assumirem um excesso de atribuições. Elas também sabem quando pedir ajuda. E os riscos que correm no cargo são calculados. Não aceitarão um desafio que sabem que não podem realizar sozinhas. Elas agirão conforme suas forças (GOLEMAN, 2015, p.15).
}

A autoconsciência é o que oportuniza a alguém possuir uma bússola interna tão forte, um norte que o oriente pela vida conforme seus valores e objetivos mais profundos, com ela é possível exatidão para decifrar a voz interior dos murmúrios do corpo. O cérebro mantém a 
mais profunda percepção de sentido e propósito de vida nas regiões subcorticais que são áreas fortemente ligadas a intuição. Os nossos valores são conhecidos primeiramente sentindo o que parece e não parece certo, e depois organizando essas sensações no nosso íntimo. Dessa forma, a autoconsciência nos possibilita sintonizar com os sutis murmúrios internos que são capazes de nos auxiliar a conduzir nossa trajetória pela vida. Este radar interno é a base para gerenciarmos o que fazemos e o que não fazemos. Para que se possa ter uma vida plena e não uma vida hesitante. Esse íntimo instrumento de controle faz toda a diferença (GOLEMAN, 2014).

Goleman (2014), também afirma que nossa mente utiliza a autoconsciência para manter tudo o que fazemos no caminho mais adequado, por exemplo, a metacognição viabiliza para que tenhamos conhecimento de como estão indo nossas operações mentais e seja possível ajustá-las se houver necessidade; a metaemoção tem a mesma função controlando o fluxo de impulsos e sentimentos. No desenho da mente, a função da autoconsciência é de gerenciamento das nossas próprias emoções, assim como de percepção em relação aos sentimentos dos outros que estão ao nosso redor.

\subsubsection{Autocontrole}

Segundo Bergman e Bell (1998), o autocontrole, respeitando o fundamento do equilíbrio emocional, não está relacionado a rigor exagerado ou intolerância. $\mathrm{Na}$ verdade, a sua essência se adéqua mais à vontade de conservar, no mais positivo dos sentidos, o controle de si mesmo. Para isso, é preciso ter conhecimento e o contato com grande diversidade de sentimentos sem a coincidência de comportamentos destrutivos ou compulsivos. As pessoas precisam de reservas suficientes de autocontrole para que consigam preservar a autodisciplina, postergar a satisfação de desejos e prazeres e suportar sentimentos desagradáveis.

Nesse sentido Goleman (2015, p. 16) afirma:

O autocontrole que é como uma conversa interior continua, é o componente da inteligência emocional que nos liberta de sermos prisioneiros de nossos sentimentos. As pessoas engajadas em tal conversa sentem mau humor e impulsos emocionais como todas as outras, mas acham meios de controlá-los e até mesmo de canalizá-los de formas úteis. 
Para Goleman (2015), não podemos eliminar os impulsos biológicos que guiam nossas emoções, porém conseguimos realizar muitas outras coisas para que possamos gerenciá-los. Gordon (2003), sugere que existe grande distância entre sentir algo e comportar-se em conformidade com isso. Para separar as duas coisas é necessário grande autocontrole.

Ainda de acordo com as ideias de Gordon (2003), mesmo que o aprendizado do autocontrole básico se origine na mais tenra idade, como no caso dos bebês, por exemplo, que são ensinados a não solicitar o impossível ou a chorar e a gritar se contrariados. O autor entende que a habilidade de gerir emoções complexas afronta até mesmo aos indivíduos com elevado grau de inteligência emocional.

De acordo com Goleman (2015), as características de autocontrole emocional são facilmente perceptíveis, sendo elas: uma tendência a ponderação e a reflexão; adequação à ambiguidade e mudança; e integridade, que é a habilidade de falar não aos impulsos. Segundo o mesmo autor, o autocontrole elevado antecipa qualidades como melhores competências interpessoais, um bom ajuste emocional e sentimentos de adaptabilidade e segurança (GOLEMAN, 2014).

Ambientes de confiança e isonomia tendem a ser criados por pessoas que estão no controle de suas emoções e impulsos, isto é, pessoas racionais. Nesses ambientes, as rivalidades e a politicagem são grandemente diminuídas e o rendimento se torna alto. Entretanto, o autocontrole as vezes pode não ser reconhecido. Indivíduos hábeis em controlar suas emoções, ocasionalmente, são interpretados como pessoas insensíveis ou indiferentes, sendo suas atitudes prudentes entendidas como desinteressadas ou sem entusiasmo (GOLEMAN, 2015).

Quanto à relevância do autocontrole no contexto profissional, Goleman (2015) destaca o grandioso valor para a liderança e sustenta que o autocontrole eleva a integridade, que é uma qualidade das pessoas, assim como uma força das organizações. Também lembra que em decorrência de comportamentos impulsivos inúmeros problemas são gerados nas empresas. Segundo Goleman (2015, p.18), “[...] pessoas raramente planejam exagerar os lucros, rechear as contas de despesas, meter a mão no cofre ou abusar do poder com finalidades egoístas." O que acontece é a apresentação de oportunidades para pessoas que possuem pouco controle de seus impulsos, e essas facilmente respondem sim. 


\subsection{Desenvolvimento da inteligência emocional}

A inteligência emocional não se trata de algo improvável de se obter. Ela pode ser fortalecida, aprimorada e expandida. Para ampliar a inteligência emocional é necessário aprender a exercitar a autoconsciência, o autocontrole e a motivação que são algumas das técnicas e aptidões que a compõem (WEISINGER, 2001).

Segundo Weisinger (2001), as emoções são capazes de proporcionar informações preciosas a respeito do próprio indivíduo, sobre outras pessoas e sobre muitos outros acontecimentos. Podemos alterar o nosso comportamento e raciocínio com a utilização das informações que as emoções fornecem, e dessa forma, reverter situações, como por exemplo, ao invés de explodir de raiva ir em busca meios de diminuir a carga de trabalho ou simplificar o processo de trabalho. Pois, como afirma Moscovici (1997, p. 17), "Nós podemos modificar a situação através do nosso comportamento. Por exemplo, se alguém nos agride, responder não agressivamente é uma forma inteligente".

As habilidades emocionais de um indivíduo como, por exemplo, as capacidades e as atitudes que utiliza para tratar da vida e do trabalho não estão geneticamente programadas, como a tonalidade da sua pele ou a cor dos seus olhos. Entretanto, em alguns aspectos, por estarem tão intimamente entranhadas na neurologia das pessoas poderiam se fazer presentes (GOLEMAN, 2015).

A experiência, segundo Goleman (2015), tem um papel relevante na forma como os genes se manifestam, embora as habilidades emocionais, em parte, sejam consideradas nascidas com o indivíduo. Existem pesquisas que propõem que, em torno dos 25 anos, as habilidades emocionais já estejam mais ou menos definidas e que a partir daí os comportamentos subsequentes já são hábitos enraizados. Para o autor, este é o problema, porque quanto mais se age da mesma forma, maior a tendência de continuar agindo da mesma forma, sendo assim, mais os comportamentos se tornam enraizados nos circuitos cerebrais. Corroborando, Gazzaniga e Heatherton (2005), afirmam que o simples fato de repetir um comportamento predispõe a sua execução de forma automática em outros momentos.

De acordo com Zaharov (2010), o ser humano é um conservador nato e, normalmente, diante da primeira dificuldade, tende a retornar para seus antigos hábitos, no entanto, para que se estabeleça a transformação de comportamento é preciso substituir hábitos. Dessa forma, se as alterações necessárias forem complexas, possivelmente, as mudanças comportamentais 
estarão propensas a serem passageiras. Uma mudança comportamental verdadeira somente acontecerá se houver uma forma de educar novamente as pessoas, reformulando seus valores e construindo hábitos novos que possibilitem felicidade, prazer, satisfação e que atendam as suas necessidades. Como cita Zaharov (2010, p. 13), "Loucura é manter as mesmas ações do passado e esperar novos resultados". Nesse sentido, Goleman (2015) relata que conexões neurais, importantes para o cérebro humano, são estimuladas quando novos comportamentos são testados e praticados em momentos distintos. Essas ações são valiosas para que ocorram mudanças verdadeiras.

Todo o ser humano é capaz de ampliar a sua inteligência emocional, porém para que ocorra é necessária uma maneira correta. Como cita Moscovici (1997, p. 16):

[...] independentemente de qualquer variável cultural, educacional, familiar, etc., todos nós podemos desenvolver esta inteligência emocional, desde que haja um processo adequado para isso. Um trabalho educacional da infância até a fase adulta e no próprio adulto também.

Para o desenvolvimento da inteligência emocional se faz necessário a ajuda de outras pessoas. Com elas é possível praticar, experimentar e receber "feedback", além disso, se torna possível avaliar a evolução do aprendizado. Aquelas pessoas consideradas próximas proporcionam o ambiente no qual é possível compreender os avanços e os benefícios do que é aprendido. Além disso, frequentemente o ser humano necessita de algum entendimento externo, pois não consegue encontrar respostas, apenas por suas próprias experiências e interesses. Esse auxílio pode ser provido por amigos, colegas e núcleo familiar de forma informal, ou de forma profissional, por um coach que irá auxiliar no entendimento, ampliação e formas de utilização de todo o potencial existente (GOLEMAN, 2015).

\section{0 que é coaching?}

O coaching promove a expansão do autoconhecimento auxiliando o participante do processo a descobrir onde ele está e a buscar meios para fazê-lo ir adiante. O sentido de vida de um cliente pode ser transformado por meio do coaching. Normalmente, ocorrem mudanças pequenas e cada uma no seu tempo, porém, no final, elas se somam (LAGES; O'CONNOR, 2015). 
Para Whitmore (2012), mediante o coaching é possível liberar toda a potencialidade existente nas pessoas e consequentemente aumentar seu próprio desempenho. Coaching é também auxiliar as pessoas a como aprender sobre alguma coisa e não ensiná-las algo diretamente. Afinal, segundo o autor, todas as pessoas possuem a habilidade de aprender naturalmente e que a instrução pode até ter efeito negativo, sendo na verdade perturbadora.

O indivíduo em um processo de coaching não obtém os fatos que necessita com o profissional que conduz o processo. Na realidade, ele é estimulado a exprimir e explorar dentro de si próprio, pois lá estão suas respostas. E tudo gira em torno de como se obtém isso da melhor forma possível, visando atingir a meta de melhorar o desempenho (WHITMORE, 2012).

Lages e O’Connor (2015) ressaltam que coaching está relacionado a metas e a realizações. O processo aproxima os sonhos da realidade. Nesse sentido, Lages e O'Connor (2015, p. 10) afirmam:

Coaching é um jogo para altas apostas. Felicidade. As pessoas recorrem ao coaching porque querem ser felizes, ou mais felizes. Elas desejam uma vida satisfatória, repleta de boas experiências. Querem bons relacionamentos, um trabalho que apreciem e que lhes de orgulho, onde possam usar seus talentos e ganhar dinheiro. Querem usufruir os prazeres da vida com intensidade. Querem ver seus melhores sonhos realizados e sentir que estão vivendo de acordo com seus mais altos valores.

O coaching é um processo interativo no qual o profissional que o conduz é chamado de coach e o cliente é chamado de coachee. Conforme Whitmore (2012), o coach não é o mesmo que um professor, um instrutor, um conselheiro, um especialista, ou, tampouco, um resolvedor de problemas. O coach é alguém que ecoa o que é apresentado pelo coachee, é um facilitador, ele também auxilia na formação de consciência. Como citam Lages e O'Connor (2015, p. 5), "Eles ajudam os clientes a se libertarem de circunstâncias desagradáveis ou insatisfatórias. Em seguida, eles abrem o leque de opções e possibilidades”.

Segundo Zaharov (2010), o coaching proporcionou às pessoas a utilização, numa escala muito maior, das suas aptidões pessoais, da sua capacidade criativa, da eficiência na resolução de problemas e produção de resultados com maior qualidade e rapidez. Para Gallwey (1996), o comprometimento em se automelhorar não é o primordial, mas sim a energia aplicada para possuir maior entendimento do poder e da beleza das próprias qualidades e daquilo que se tornou. 


\subsection{Ferramentas do coaching - Perguntas e crenças}

Segundo Lages e O’Connor (2015), uma pergunta classificada como "boa" irá clarear áreas diferentes, ou seja, expandir a consciência de si próprio. Para o autor, quando uma pergunta valiosa é feita para um cliente é oferecido a ele a chance de estudar seus recursos e experiência de uma forma distinta, e de localizar respostas que ele não fazia ideia que poderia possuir. Afinal, os clientes, frequentemente, buscam as soluções nos lugares que já são conhecidos, porém, as soluções não serão localizadas lá; caso contrário o cliente já as teria obtido. Os autores afirmam que, "as perguntas são como pontos de luz que brilham em lugares escuros" (LAGES; O’CONNOR, 2015, p. 91).

\footnotetext{
Num mundo complexo, no qual quase todos têm acesso à mesma informação, surge um novo valor da síntese original, da união de ideias de forma inovadora e das perguntas inteligentes que ativam potenciais intocados. Insights criativos implicam a junção de elementos de um modo útil e original (GOLEMAN, 2014 p. 49).
}

Assim como refletem luz, as perguntas também colocam outras áreas no escuro, ou seja, elas orientam a atenção do cliente para certos assuntos e, logo, afastam de outros. Perguntas acertadas conseguem informações eficientes e com frequência elucidam o que um cliente quer dizer com exatidão. Também podem ser usadas para aumentar as possibilidades do cliente confrontando os seus limites autoimpostos (LAGES; O’CONNOR, 2015).

Segundo Dilts, Hallbom e Smith (1993, p. 111), crenças "são regras de sua vida, as regras pelas quais você vive". Representam a estrutura mais significativa do comportamento. O comportamento do individuo será coerente com sua crença quando de fato acreditar naquilo. Para Lages e O’Connor (2015), é preciso observar o que uma pessoa faz para compreender no que, realmente, ela acredita, e não apenas ouvir o que ela diz acreditar.

De acordo com Lages e O’Connor (2015), as crenças são formadas a partir das experiências e por isso são entendidas como verdades. Além disso, as experiências vividas também sofrem influência das crenças, pois cada realidade do ser humano é criada e sustentada por elas. Por exemplo, se uma a pessoa acredita que é uma companhia agradável ela agirá como tal, e irá se aproximar e manter-se na companhia de outras pessoas. Sendo 
assim, “sob certo sentido elas são profecias auto-realizáveis” (LAGES; O'CONNOR, 2015, p. 111).

Para Martins (2015), quando as crenças promovem alterações no pensamento e impossibilitam as pessoas de adotar comportamentos assertivos, elas podem ser entendidas como crenças que não racionais. É possível dar um novo significado ao pensamento, transformar a forma como se vê uma situação, essa alteração de crença é chamada de ressignificação.

Como cita Martins (2015, p. 105) "você pode mudar a visão de uma situação ruim para outra mais produtiva, alterando o conteúdo do pensamento negativo para positivo. Isso é autoconhecimento e autoconsciência". A ressiginificação de crenças, como abrange O'Connor (2015), é sobre alterar a forma pela qual as pessoas compreendem os acontecimentos e, consequentemente, tornam o seu significado diferente. Segundo o mesmo, tem-se o entendimento de que ao alterar o significado as atitudes e comportamentos também se tornarão diferentes.

\section{Desenvolvendo autoconsciência e autocontrole utilizando ferramentas de coaching - perguntas e crenças}

Segundo Whitmore (2012), a consciência é o elemento principal e inicial do coaching, ela é fruto da compreensão e da atenção. Estar consciente envolve compreender e interpretar aquilo que se observa ou sente. Assim como, existem recursos que aumentam a eficiência dos sentidos da visão e da audição, a consciência também pode ser aumentada sem a necessidade de utilização de medicamentos, apenas pela prática e pela atenção. Através do coaching é possível expandir a consciência tornando compreensíveis os atributos físicos e mentais das pessoas e desenvolver a habilidade de melhorar a si mesmo sem a necessidade de aval de outras pessoas, ampliando a autoconfiança. A consciência também inclui o autoconhecimento, principalmente, percebendo de que forma as emoções e os desejos alteram a compreensão dos fatos.

Ter conhecimento sobre o que orienta as ações provê solidez para que as pessoas façam escolhas corretas e possam iniciar uma mudança de comportamento. É necessário entender o que é importante, a forma como se vivenciam as situações, aquilo que se deseja e 
como se comunica com outras pessoas. De acordo com o autor, momentos de profunda reflexão e determinação para estudar as próprias reações são a base para amplificar a autoconsciência (WEISINGER, 2001).

Conforme Weisinger (2001), informações são valiosas. Ter consciência da grande quantidade que está ao alcance dos indivíduos como, por exemplo, suas próprias avaliações, sensações, sentimentos, intenções e ações pode ajudar na compreensão de como agem, reagem, comunicam e atuam em diversas situações. Processar todas essas informações se traduz em autoconsciência. De acordo com Lages e O'Connor (2015), no coaching as perguntas são fontes de informações e parte fundamental do processo. Elas têm vários objetivos. As primeiras sessões servem para conseguir dados e determinar acontecimentos. Em seguida, são utilizadas para investigar as crenças e valores, para compreender profundamente o cliente. Além disso, as perguntas são realizadas para que seja possível verificar perspectivas diferentes ou novas possibilidades.

As perguntas atuam gerando consciência e responsabilidade. Contudo, nem todas têm a mesma eficiência, por exemplo, as perguntas fechadas - de respostas "sim" ou "não" limitam a busca por detalhes. Como cita Whitmore (2012, p 64) "elas nem se quer obrigam a pessoa a usar o cérebro". No entanto, as perguntas abertas, que requerem respostas elucidativas, são poderosas para potencializar a consciência (WHITMORE, 2012).

Conforme Gordon (2003), a consciência do que sente é o atributo principal da inteligência emocional. Potencializar a consciência significa ter maior entendimento sobre o que acontece no âmago do indivíduo, processar esse conhecimento significa aumentar a autoconsciência (WEISINGER, 2001).

Os componentes da inteligência emocional, principalmente a autogestão, têm a sua essência na autoconsciência, pois como afirma Weisinger (2001, p. 26):

\footnotetext{
A autoconsciência está no cerne de cada uma dessas aptidões, porque a inteligência emocional só pode começar quando a informação entra no sistema perceptivo. Por exemplo: para conseguir controlar a raiva, você tem que ter consciência daquilo que a provoca e de como essa poderosa emoção o afeta - então poderá aprender a reduzila e usá-la acertadamente [...]
}

Segundo Goleman (2014), quando as pessoas ficam fora de controle e agem de maneira indelicada, frequentemente, não estão discernindo seus atos. Conforme, Dilts, Hallbom e Smith (1993), o processo de mudança tem início quando a pessoa decide o seu objetivo, pois a partir desse momento o seu cérebro irá trabalhar inconscientemente para 
alcançá-lo, mandando informações que corrigirão os comportamentos que possam desviar da direção do objetivo que foi definido.

De acordo com Mischel e Shoda (apud Gazzaniga e Heatherton, 2005) a forma como as pessoas reagem as situações sofre influência da sua percepção emocional, das competências e habilidades que dispõem e de certa noção dos resultados que poderá produzir pelo seu comportamento. Para Goleman (2014), a capacidade de nomear os sentimentos e integrar as memórias e associações é crucial para o autocontrole.

Segundo Goleman (2015), as pessoas se diferenciam quanto as suas experiências, gostos, predileções, temperamentos, compromissos, medos, aflições e por aquilo que acreditam. As crenças, como indicam Dilts, Hallbom e Smith (1993), formam experiências de vida, mas igualmente são fruto de experiências vividas. Eles afirmam que, o início de qualquer mudança parte do trabalho com o sistema de crenças de cada indivíduo.

De acordo com Dilts, Hallbom e Smith (1993), o trabalho com o sistema de crenças começa entendendo a necessidade do cliente, reunindo informações sobre seu estado atual e comparando como estado desejado. De maneira simplificada, o trabalho consiste em alterar a forma como se percebe experiências vividas. É formado um novo significado, e assim, transformado o modo como se sente e reage a elas. Como afirmam Lages e O'Connor (2015), as crenças se modificam como resultado da experiência e as experiências se transformam com a alteração das crenças.

Conforme Zaharov (2010), não é possível mudar o mundo para que se esteja completamente satisfeito com a própria vida, porém, é possível reexaminar as próprias regras que o conduzem pela vida e alterar a forma de enxergar e reagir ao mundo. Segundo Goleman (2015), no coaching, não raro, o profissional apenas auxilia o cliente a identificar o que internamente, em algum nível, ele já conhece. Ainda de acordo com o autor, a forma como as pessoas reagem as situações está relacionada à memória que possuem delas, sendo assim, é possível reagir de forma diferente transformando essas lembranças.

[...] nossa atenção se estreita, colada ao que está nos perturbando, nossa memória se embaralha, tornando mais fácil recordar qualquer coisa que seja relevante à ameaça em questão. E nosso corpo entra em marcha acelerada enquanto uma enxurrada de hormônios do estresse prepara nossos membros para lutar ou correr. Nós nos fixamos naquilo que é perturbador e esquecemos o resto (GOLEMAN, 2014, p. 42). 
Corroborando, Gallwey (1996) afirma que existem somente duas maneiras para lidar com situações incômodas no presente. Uma opção é alterar a situação; a outra é transformar a mente de quem está vivenciado o incômodo.

\section{Considerações finais}

Com o presente estudo, buscou-se compreender a evolução das capacidades da inteligência emocional através do processo de coaching. Para isso, foi realizada pesquisa bibliográfica em materiais relacionados ao tema proposto, dentre os materiais pesquisados estão: livros, artigos científicos e revistas de negócios.

Através da pesquisa, se pôde verificar que as capacidades da inteligência emocional são passíveis de desenvolvimento e que o coaching pode auxiliar e ter papel importante nesse processo. Para delimitar o campo de estudo (porque o coaching possui diversas ferramentas), foram utilizadas na pesquisa as ferramentas Perguntas e Crenças buscando compreender seus papéis no desenvolvimento dos componentes da inteligência emocional.

Um dos objetivos do estudo aqui apresentado era entender de que forma o componente autoconsciência poderia ser desenvolvido através do processo de coaching. Por meio da pesquisa, foi possível compreender como o coaching pode atuar para promover a expansão da autoconsciência do cliente.

Para responder ao objetivo proposto foi estudada a ferramenta Perguntas. As perguntas, se realizadas de maneira correta, podem estimular o cliente a pensar de uma forma diferente, encontrar respostas novas para situações já conhecidas e ampliar as suas possibilidades. Elas podem elevar a consciência do cliente, tornando-o lúcido quanto aos seus pontos fortes e a melhorar.

As perguntas auxiliam na obtenção e na compreensão de informações que são fundamentais para ampliar a consciência do cliente, promovendo reflexão e posterior entendimento das suas questões mais profundas. Constatou-se que processar o conhecimento adquirido com ampliação da consciência resulta em desenvolvimento da autoconsciência.

Outro objetivo do trabalho era entender de que forma o componente autogestão pode ser desenvolvido através do processo de coaching. Com a pesquisa, foi entendido que é 
possível desenvolver esse componente e, para isso, foi estudado a ferramenta chamada Crenças.

A autogestão é o componente da inteligência emocional, relacionado à forma como as pessoas reagem às situações. Essas reações podem ser impulsivas ou pensadas. Quando as pessoas conseguem dominar seus sentimentos e ter reações pensadas entende-se que tenham a autogestão desenvolvida. O fato é que as reações são influenciadas pela percepção das pessoas, por associações e por suas memórias de situações vivenciadas, caso esses fatores tenham sido desagradáveis as reações tendem a não ser coerentes como momento atual e sim baseadas em experiências anteriores.

As crenças, no processo de coaching, auxiliam na ressignificação de experiências, tornando-as coerentes e produtivas. Por esse motivo, ajudam no desenvolvimento da autogestão, pois possibilitam perceber situações já vividas de maneira diferente. Isso resulta em novos sentimentos e novas formas de reagir frente a essas situações.

Portanto, os entendimentos obtidos com a pesquisa bibliográfica mostram que a inteligência emocional consegue ser ampliada por meio de processo de coaching, assim como seus componentes autoconsciência e autogestão. E que as ferramentas do coaching Perguntas e Crenças são úteis para desenvolvimento desses componentes. Contudo, cabe ressaltar que o desenvolvimento da inteligência emocional abrange, também, outros aspectos que não foram abordados nesse estudo. Além disso, existem diversas ferramentas do coaching que não foram apresentadas. Um estudo mais aprofundado traria maior compreensão e riqueza de detalhes ao tema que é atual e importante para o desenvolvimento das pessoas.

O estudo do desenvolvimento da inteligência emocional por meio do coaching mostrou que existe um vasto campo de conhecimento a ser explorado. Com possibilidades para pesquisas futuras como, por exemplo, estudos empíricos. Essas pesquisas poderiam testar na prática os achados desse estudo e contribuir para aumentar a bibliografia existente.

\section{Referências}

BERGMAN, R. L; BELL, A. W. Condicionamento do equilíbrio emocional: o primeiro plano de ação para você ter uma saúde emocional definitiva. São Paulo: Ed. Cultrix, 1998. 
CAVALCANTI, V. L. \& CARPILOVSKY M. \& LUND, M. \& LAGO, R. A. Liderança e Motivação. Rio de Janeiro: Ed. FGV, 2009.

CRESWELL, J. W. Projeto de pesquisa: métodos qualitativo, quantitativo e misto. 3.Ed. Porto Alegre: Artmed, 2010.

DILTS, R. B; HALLBOM, T.; SMITH, S. Crenças: caminhos para a saúde e o bem estar. São Paulo: Ed. Summus, 1993.

GALLWEY, W. T. O jogo interior de tênis. São Paulo. Ed. Textonovo, 1996.

GAZZANIGA, M. S; HEATHERTON, T. F. Ciência psicológica: mente, cérebro e comportamento. Porto Alegre: Artmed, 2005.

GOLEMAN,, D. \& McKEE, R. B. O Poder da Inteligência Emocional: a experiência de liderar com sensibilidade e eficácia. Rio de Janeiro: Ed. Elsevier, 2002.

GOLEMAN, D. Inteligência emocional: a teoria revolucionária que redefine o que é ser inteligente. Rio de Janeiro: Ed. Objetiva, 2011.

GOLEMAN, D. Foco: a atenção e seu papel fundamental para o sucesso. Rio de Janeiro: Ed. Objetiva, 2014.

GOLEMAN, D. Liderança: a inteligência emocional na formação de um líder de sucesso. Rio de Janeiro: Ed. Objetiva, 2015.

GORDON, C. Você é mais esperto do que pensa? Mais de 150 testes para ajudá-lo a descobrir e explorar a sua inteligência natural. São Paulo: Ed. Cultrix, 2003.

KERKOSKI, J. M. Prática desportiva e inteligência emocional: estudo da influência do desporto na aquisição de aptidões e competências de inteligência emocional. 2008. $338 \mathrm{f}$. Tese (Doutorado em Estudos da Criança) - Instituto de Estudos da Criança, Universidade do Minho, Braga.

LAKATOS, E. M.; MARCONI, M. de A. Fundamentos de metodologia científica. 7.Ed. São Paulo: Atlas, 2010.

LAGES, A.; O'CONNOR, J. Coaching com PNL: o guia prático para alcançar o melhor em você e em outros: como ser um coach master. Rio de Janeiro. Ed Qualitymark, 2015.

MARTINS, Vera. O emocional inteligente: como usar a razão para equilibrar a emoção. Rio de Janeiro. Ed. Alta Books, 2015

MOSCOVICI, F. Razão \& Emoção:a inteligência emocional em questão. Salvador: Ed. Casa da Qualidade, 1997.

O'CONNOR, J. Manual de programação neurolinguistica: PNL: um guia oratico para alcançar os resultados que você quer. Rio de Janeiro. Ed. Qualitymark, 2015.

RYBACK, D. Emoção no local de trabalho: o sucesso do líder não depende só do Q.I. São Paulo: Ed. Cultrix, 1998. 
SILVEIRA, B. Minidicionário da língua portuguesa. Edição revisada e atualizada. São Paulo: Ed. FTD, 2002.

THUMS, J. Acesso à realidade: técnicas de pesquisas e construção do conhecimento. Porto Alegre: Sulina: Ulbra, 2000.

WEISINGER, H. Inteligência emocional no trabalho: como aplicar os conceitos revolucionários da I.E nas suas relações profissionais, reduzindo o estresse, aumentando sua satisfação, eficiência e competitividade. Rio de Janeiro: Ed. Objetiva, 2001.

WHITMORE, J. Coaching para aprimorar o desempenho: as princípios da prática do coaching e da liderança. CIDADE: Ed. Clio, 2012.

ZAHAROV, A. Coaching: caminhos para transformação da carreira e da vida pessoal. Rio de Janeiro: Ed. Brasport, 2010. 